\title{
Parametric study on structural behavior of a two-span continuous bridge deck and a curved span deck
}

\author{
Tirimisiyu Abiodun Buari, ${ }^{1,3}$ Festus A. Olutoge, ${ }^{1,2}$ Gbenga M. Ayininuola, ${ }^{1}$ Agbanah-Owa Olunipin ${ }^{1}$ \\ ${ }^{1}$ Department of Civil Engineering, University of Ibadan, Nigeria \\ ${ }^{2}$ Faculty of Engineering, the University of the West Indies, Trinidad \\ ${ }^{3}$ Department of Building Technology, the Federal Polytechnic Ede, Nigeria
}

\section{Keywords}

Grillage Analysis,

Finite Element Analysis,

Bridge Modeling,

Bridge deck,

Sap2000,

CSI Bridge,

Continuous Bridge Deck.

\begin{abstract}
This research investigated the comparative structural response of a straight and curved continuous bridge deck subjected to realistic working loads. The study involved examining the variance in analysis results obtained while utilizing the grillage and finite element methods for an idealized bridge deck. The combined impact of continuity at the intermediate support and the curvature on the overall structure was examined. The idealized case study is a $45 \mathrm{~m}$ two-span continuous bridge deck with a $22.5 \mathrm{~m}$ straight span and an equivalent $22.5 \mathrm{~m}$ curved span with a centerline radius of approximately $14.32 \mathrm{~m}$. The bridge deck was designed for design dead load and 45 units of HB load, these loads were computed based on recommendations given in BS 5400-2:2006 and BD 37/01-1:2001[1,2]. For the Grillage Analysis Sap2000 version 22 software was utilized while CSI Bridge version 21 was used to simulate the Finite Element model. The findings from the study revealed that the results obtained from the grillage analysis method were more conservative with respect to midspan sagging moments and support shear force. However, the finite element analysis result was more conservative for support hogging moments, deflection and torsional moments. It was concluded that finite element analysis result values differed from the grillage analysis, but the values were close enough with the disparity not calling for serious concerns.
\end{abstract}

\section{Introduction}

Today Nigeria is facing the challenge of declining infrastructure, this problem is particularly evident in its public infrastructure and bridges. In recent times, Lokoja-patiji and third mainland bridge which are prominent national bridges in Nigeria have had to undergo intermittent shut-downs and repairs most particularly due to failing bridge joints.

Bridge decks have variant forms and profiles. However, when considering the horizontal profile a bridge is typically regarded as either straight or curved. Skew decks also exist and the structural behaviour of this type of decks have been investigated by researchers; Himansha and Yogesh, (2014)[3]; Pranathi and Karuna(2015)[4].

Abundance of research work has been done in the past on investigating the structural response of One dimensional and two dimensionally oriented structural elements (i.e. beam elements, plate elements). Findings from investigations notably by Timoshenko (1953)[5] and Truesdell (1960)[6]formed the foundation principle for the formulation of beam bending and plate theory.

Majority of such prior research examined the structural response of these elements acting independent of other adjoining structural members. However, in reality, structural members are connected and the assemblage of these elements is what makes up the entire structure.

This study thus focusses on investigating the structural response of an idealised two-span continuous bridge deck with one span being horizontally straight while the other span being an equivalent curved span. To investigate the structural response of bridge structures, the grillage and finite element analysis methods are generally adopted methods utilized by most engineering professionals worldwide. The general guidelines for executing grillage analysis for bridge decks were outlined by Hambly (1976)[7].
The objective of this research is to investigate the impact of adopting the grillage or finite element analysis approach in continuous bridge decks whilst examining the impact of curvature on the structural response results. Thereby enabling a consideration for viable alternative solutions to local bridge construction challenges in Nigeria. The approach adopted was to create a realistic scenario of a continuous straight and curved deck of identical span lenghts and then examine its structural response under the impact of practical working loads. Thus investigating the combined influence of continuity and horizontal profile curvature on the structural response of bridges.

A very similar study was executed by Medhat(2016)[8], where the structural response of a composite curved bridge deck was understudied.The model had a reinforced concrete slab and steel girders beneath the slab deck. A meticulous analysis was conducted utilizing CSI Sap2000 version 9 and ANSYS for 3D finite element simulation. However, in this study, a two-span continuous reinforced concrete bridge deck was considered with the straight span transiting into a curved span at the intermediate support. The grillage analysis was done utilizing CSI Sap2000 version 22 [9] whilst the 3D finite element analysis was executed with CSI Bridge version 21 [10].

\subsection{Importance of Research}

The essence of this research is to examine viability of continuous bridge decks in solving Nigeria's local bridge maintenance challenges.

To examine the influence of curvature on the structural response of bridge girders. Hence, leading to improved design of similar structures in the future. 


\section{Methodology}

The methods adopted for this research is classified into two:

1. Computer Analysis comprising of;

- Grillage Analysis

- $\quad$ Finite Element Analysis.

2. Experimental Investigation (Dimensional Analysis and Similitude).

To facilitate the research an idealized case study model was adopted. This model has the unique form of a deck built off the rear end of a typical "S" curve.

The horizontal profile was chosen to enable investigation of the structural response of the bridge deck under varying scenario of curved and equivalent straight spans. The straight span and the curved span have equal $22.5 \mathrm{~m}$ spans when measured along the centerline of the deck, thus enabling a comparative examination of how a continuous straight span performs when compared to an equivalent curved span under the impact of similar loading conditions.

The cross-section and plan layout of the bridge deck is as shown in figures 1 and 2 respectively. The design loads were computed for based on BS 5400-2:2006 and BD 37/01-1:2001[1,2] recommendations and then a grillage analysis was conducted following guidelines outlined in Hambly (1976)[7].Sap2000 version 22 analysis software was utilized for the analysis; the grillage layout is as shown in figure 3.

The 3D finite element analysis model was designed to replicate the grillage analysis model.The finite element model was subjected to the same loading conditions with the grillage analysis model and this is depicted in figure 4.

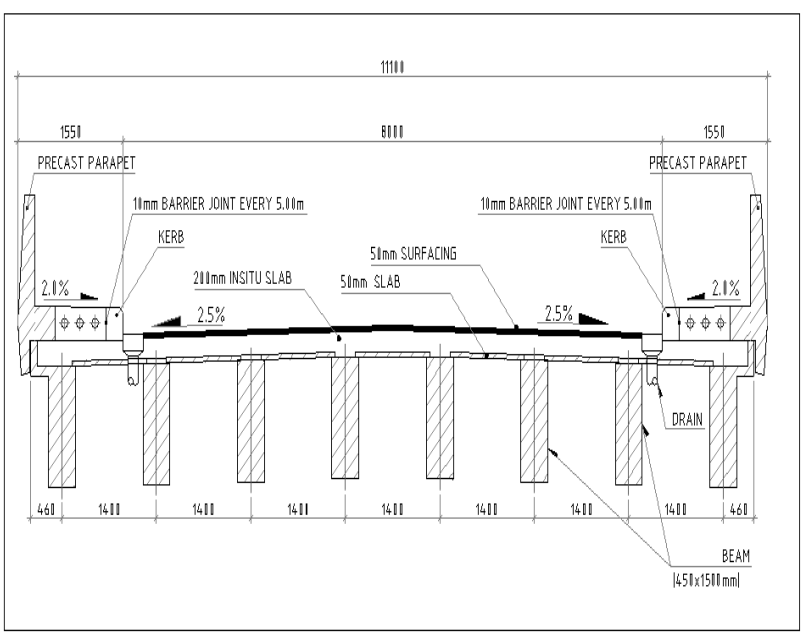

Figure 1. Typical Cross-Section of Bridge deck.

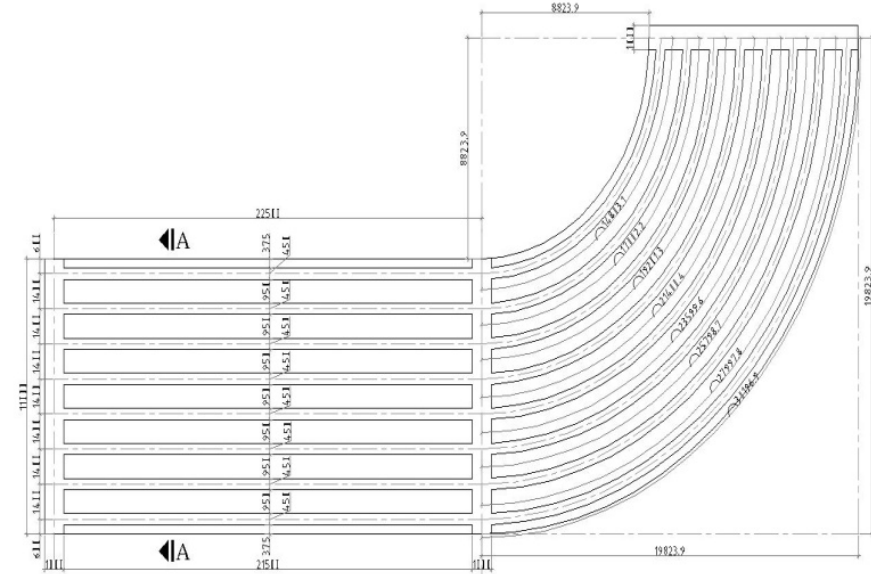

Figure 2. Typical Plan of Idealized Bridge Deck.

Support restraints were simulated at the end and intermediate mid support locations of the deck; generally, six directions of fixity exist, three for translation and three for rotation.

For the experimental model, a scaled-down model was created based on similitude requirements in accordance with the recommendations of Muller (1992), Van and Robert (1968)and Gang et al (2010)[11-13].

A convenient scale had to be chosen for the physical model, and main factors that determined the scale chosen were the practicability of sizing down materials and availability of small-sized reinforcement bars for the scaled-down model.

The bridge was scaled down to a 1:20 scale hence, the entire $45 \mathrm{~m}$ span was reduced to $2.25 \mathrm{~m}$ when measured along the centreline of the deck based on similitude requirements. The width of the deck was scaled from $11 \mathrm{~m}$ to $0.55 \mathrm{~m}$ and the depth of the slab from $0.25 \mathrm{~m}$ to $0.0125 \mathrm{~m}$, the beam dimensions from the bottom of the slab scaled from $1.5 \mathrm{~m} \mathrm{x} 0.45 \mathrm{~m}$ to $0.075 \mathrm{~m} \times 0.0225 \mathrm{~m}$

The 1:20 scale was chosen because it allowed the use of $6 \mathrm{~mm}$ diameter reinforcement bars for the girders, the $6 \mathrm{~mm}$ bars is the smallest available reinforcement bar in the local market. For the beam stirrup and slab deck, mild flexible steel rods were used to replicate the reinforcement bars, plate 1 shows the scaled-down bridge deck model with girder and deck reinforcement arranged.

For the reinforced concrete casting, the following materials were utilized for casting; fine aggregate, portland cement, small-sized coarse aggregate, BASF MasterGlenium 118 super-plasticizer and potable water. Batching by weight was adopted with the mixing ratio of 1:1:2 and a water-cement ratio of 0.45 . The mixing was done manually.

Plate 2 shows the completed scaled-down bridge after casting was completed. 


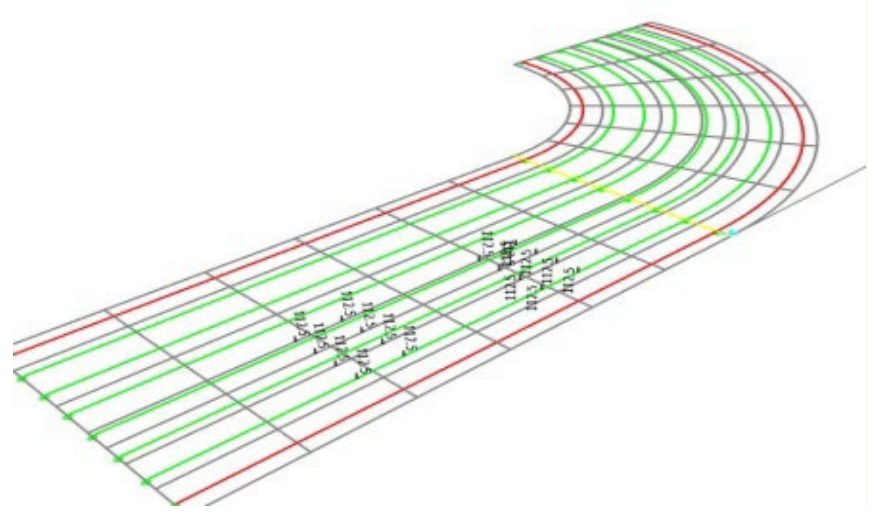

Figure 3. Sap2000 Bridge Deck Grillage Layout.

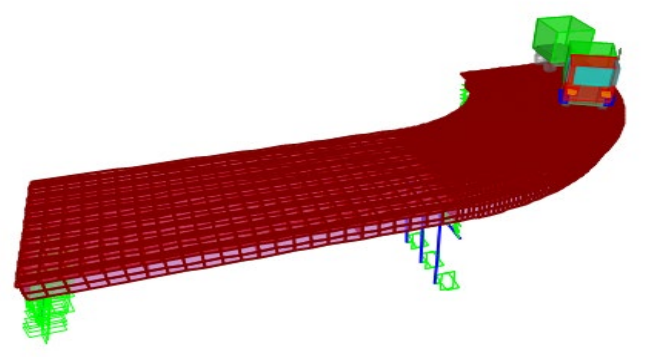

Figure 4. CSI Bridge Finite Element Layout

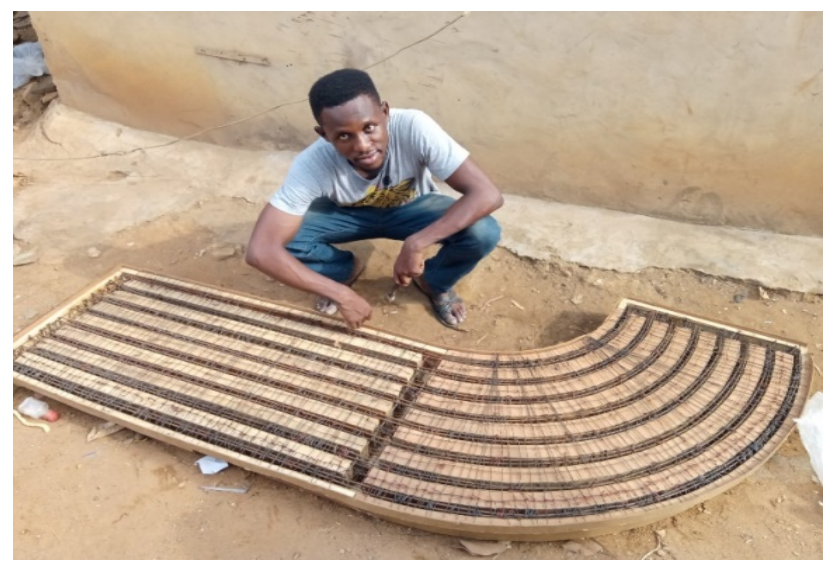

Plate 1. Reinforcement arranged in scaled-down bridge deck formwork.

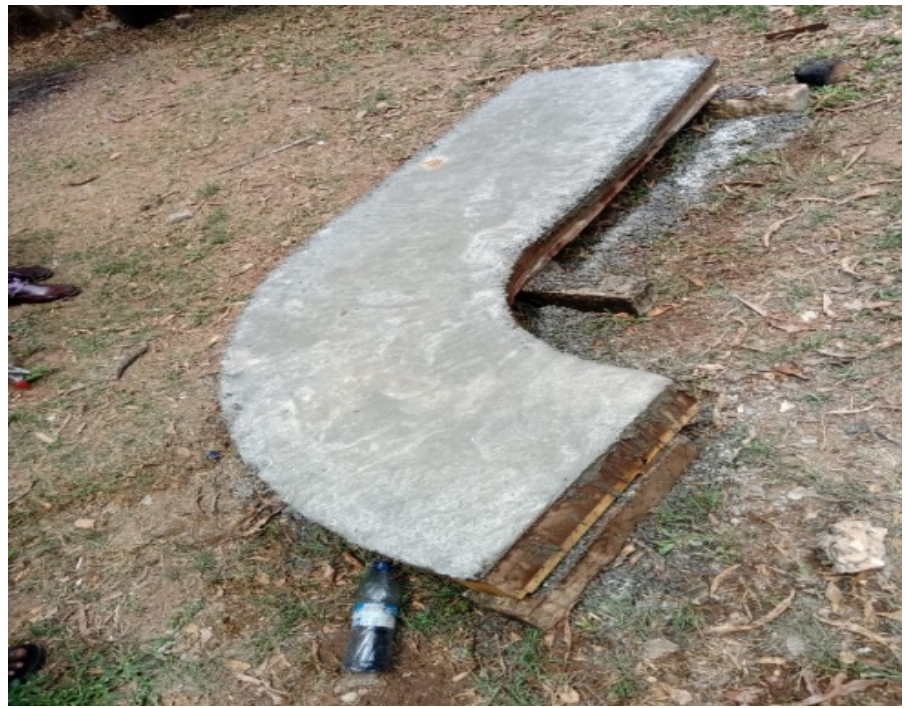

Plate 2. Model Bridge Deck after Casting.

\section{Results and Discussion}

The results obtained from the grillage and finite element were compared, this involved comparing results obtained for each girders of the deck labelled 1-8. Girder 1 is the left exterior girder,while girder 8 is the right exterior girder.

Girders 1-8 on the straight span of the deck have identical span lengths. However, the position of HB load on the decks' notional lane would be a major variable that would make results on each girder to differ. Girders 1-8 of the curved span of the deck have varying span lengths with girder " 1 " having the longest length of approximately $30.2 \mathrm{~m}$ and girder "8" having the shortest length of approximately $14.8 \mathrm{~m}$. Tabulated below are figures $5-17$ showing the summary of the compiled analysis results obtained.

To understand the impact of the curvature on the bridge decks structural response, it is important to pay close attention to girder 4 and 5 of the curved span of the deck. This is because these girders have a span length of approximately $23.6 \mathrm{~m}$ and $21.4 \mathrm{~m}$ respectively.These girders have lengths that are very close to the $22.5 \mathrm{~m}$ spans of the straight girders. The sagging moments for the straight span and curved span for girder 4 differed by $6.16 \%$ in the grillage analysis result and $21.44 \%$ in the finite element analysis result. In girder 5 , the grillage analysis result for the straight span differed the curved span by $19.05 \%$ and $5.28 \%$ in the finite element analysis result. Hence, it can be concluded that the resulting bending moment for a curved beam is higher than that of an equivalent straight beam. The experimental model created posed several challenges, from finding a suitable scale with materials that will replicate the actual bridge model as materials to simulate the scaled-down model did not perfectly conform to similitude requirements, mild steel $6 \mathrm{~mm}$ diameter reinforcement bars were used as main reinforcement and binding wires were used for the stirrups and deck reinforcement. Hence, the deformation on the physical model exceeded design expectations. It is recommended that for more coherent results a smaller scale of about 1:10 should be utilized as opposed to the 1:20 which was adopted for this study. Because it will enable the utilization of bigger reinforcement bar sizes with the better bond strength and thus result in generating more admissible results. 
Finite Element Analysis and Grillage Analysis Results For Mid Span Sagging Moments in the Straight Span

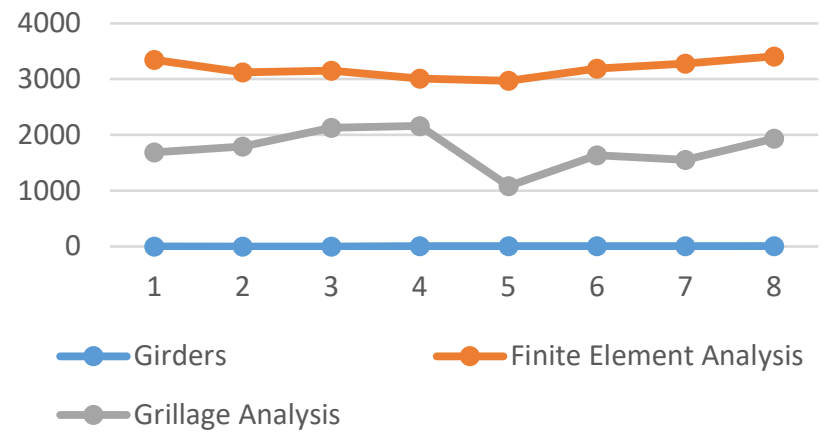

Figure 5. Finite Element Analysis and Grillage Analysis Results for Mid Span sagging moments in the Straight Span.

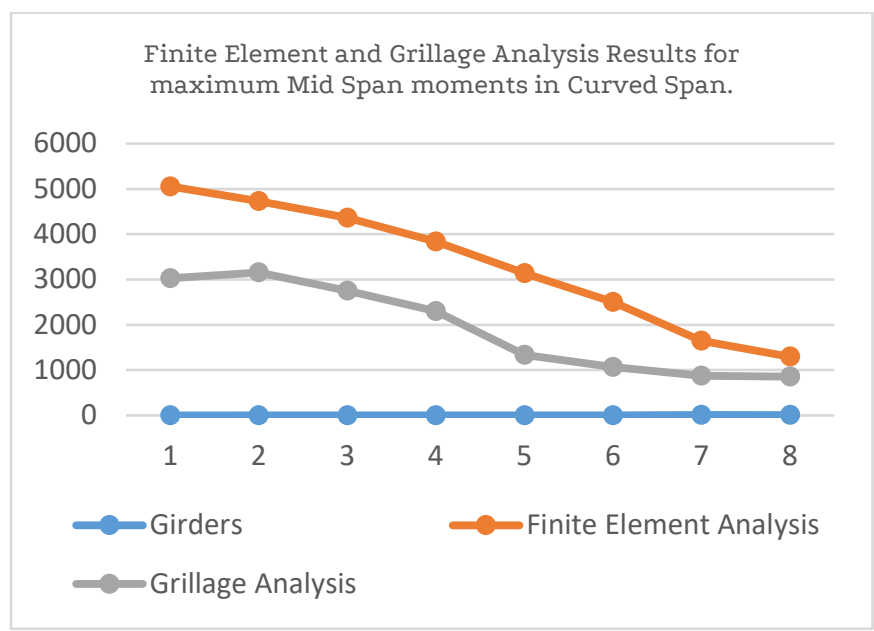

Figure 8. Finite Element Analysis and Grillage Analysis Results for Mid Span Sagging moments in the Curved Span.

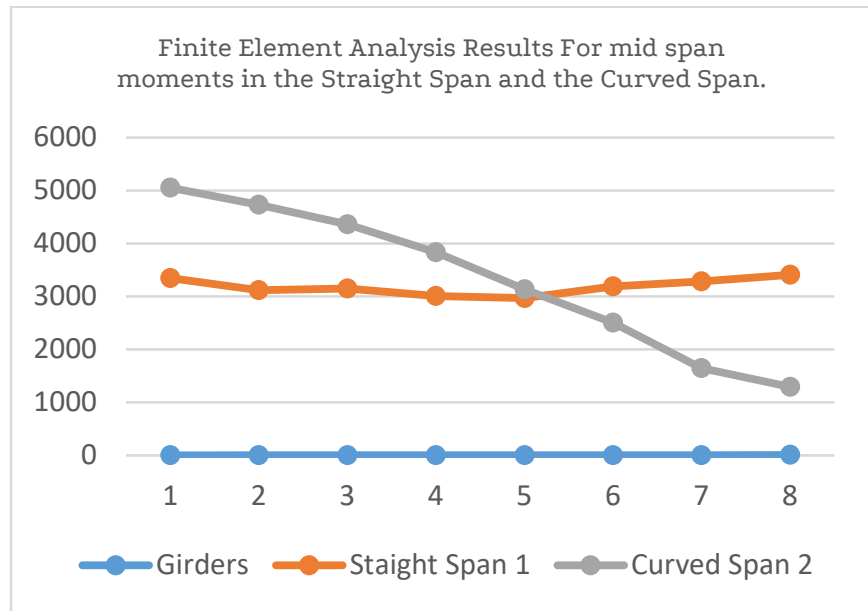

Figure 6. Finite Element Analysis Results for Mid Span Sagging Moments in the Straight and Curved Span.
Grillage Analysis Results For Mid Span Moments in Straight and Curved Spans.

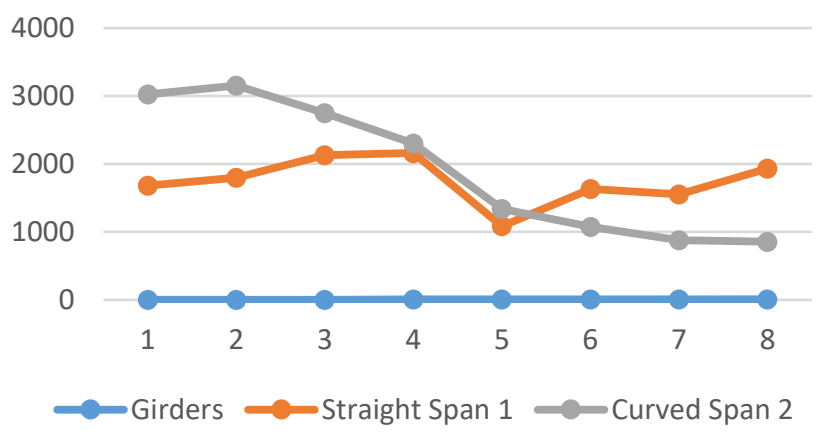

Figure 7. Grillage Analysis Results for Mid Span Sagging Moments in the Straight and the Curved Spans.

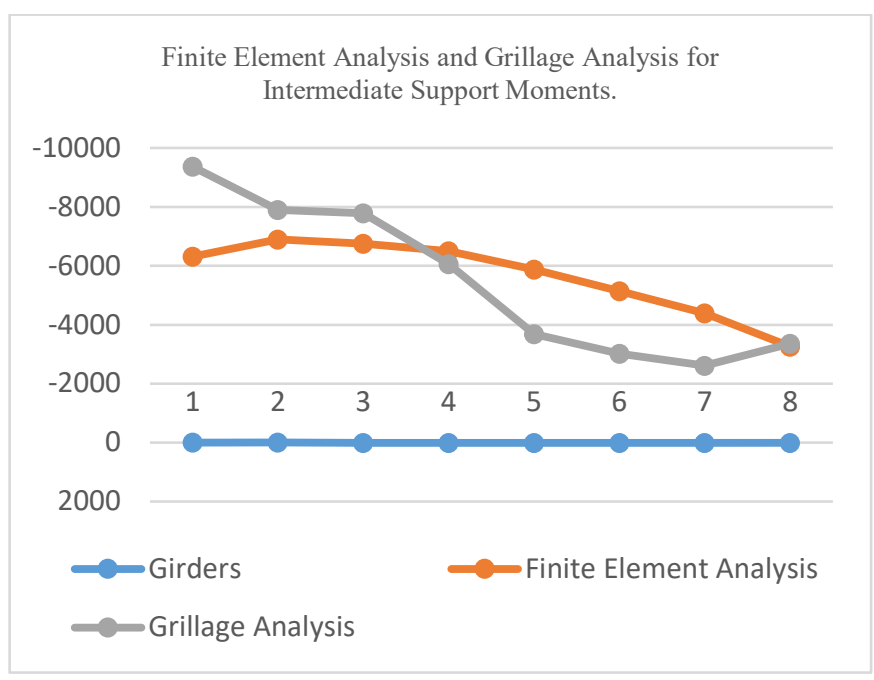

Figure 9. Finite Element Analysis and Grillage Analysis Results for Intermediate Support Hogging moments.

Finite Element and Grillage Analysis for Straight Span Left-Hand Support Shear Force.

1000

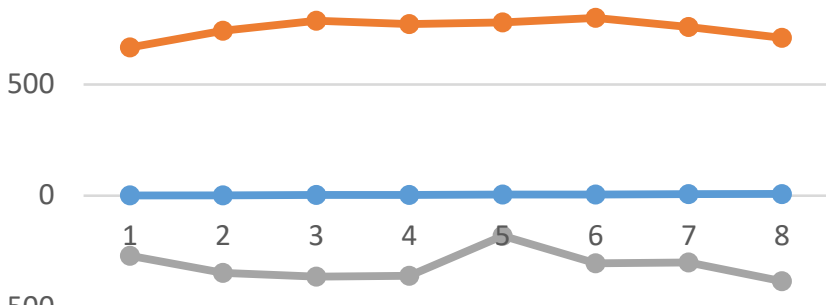

$-500$

- Girders - Finite Element Analysis - Grillage Analysis

Figure 10.Finite Element Analysis and Grillage Analysis Results for Shear Force at the Left-hand support of the Straight Span. 


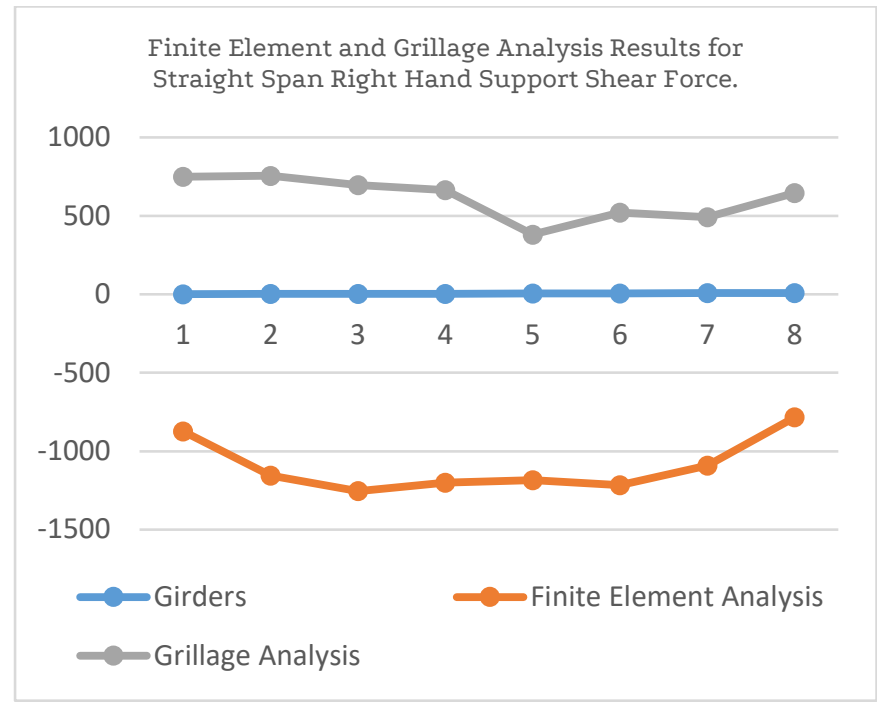

Figure 11. Finite Element Analysis and Grillage Analysis Results for Shear Force at the Right-Hand support of the Straight Span.

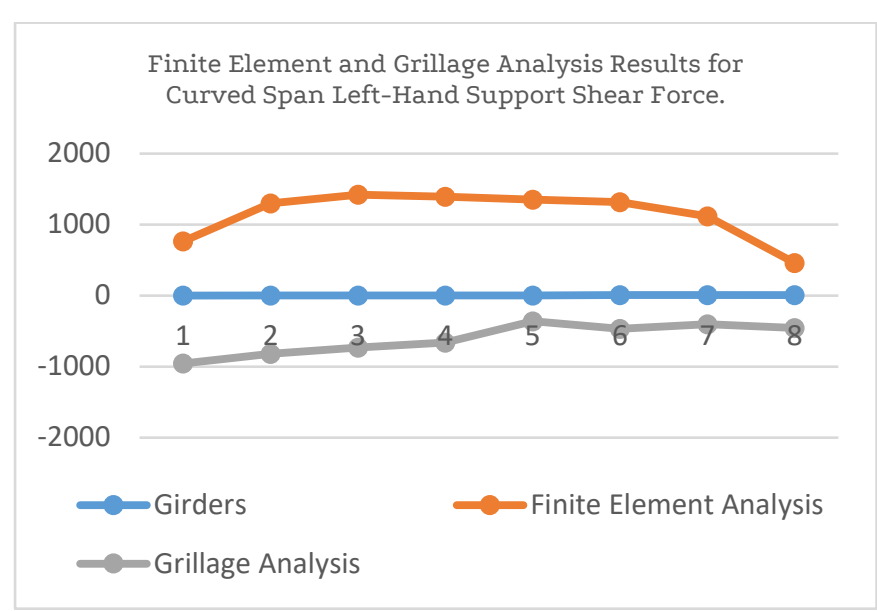

Figure 12. Finite Element Analysis and Grillage Analysis Results for Shear Force at the Left- hand support of the Curved Span.

Finite Element Analysis Results for Straight Span Right Hand Support and Curved Span Left Hand Support Shear Force.

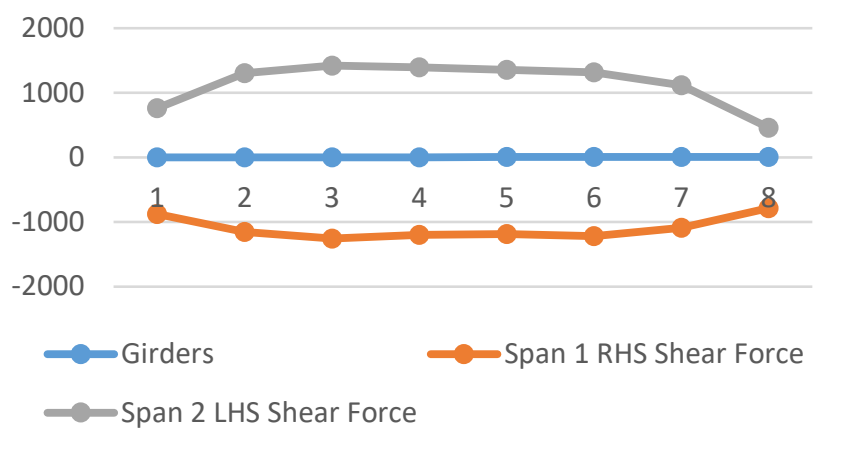

Figure 13. Finite Element Analysis Results for maximum Shear Force at the Right-Hand Support of Straight Span and the Left -hand support of Curved Span.
Grillage Analysis Results for Straight Span Right Hand Support and Curved Span Left Hand Support Shear Force.

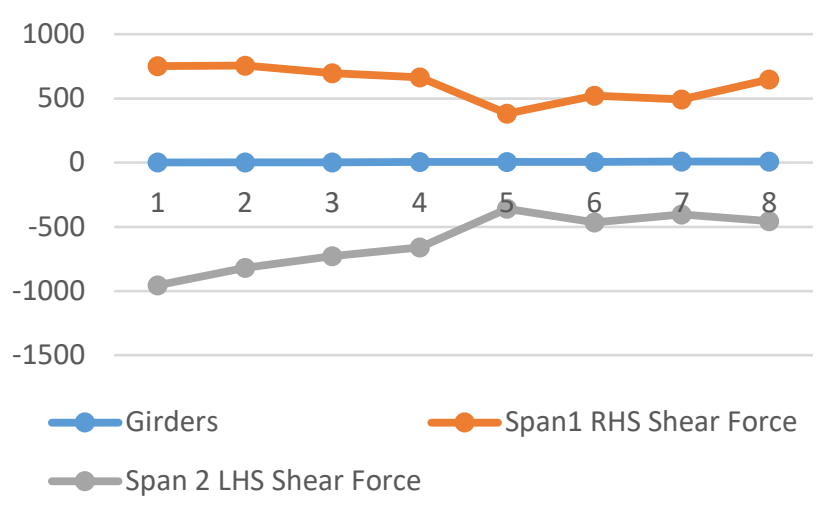

Figure 14. Grillage Analysis Results for Shear Force at the Right-Hand support of the Straight Span and the left- hand support of the Curved Span.

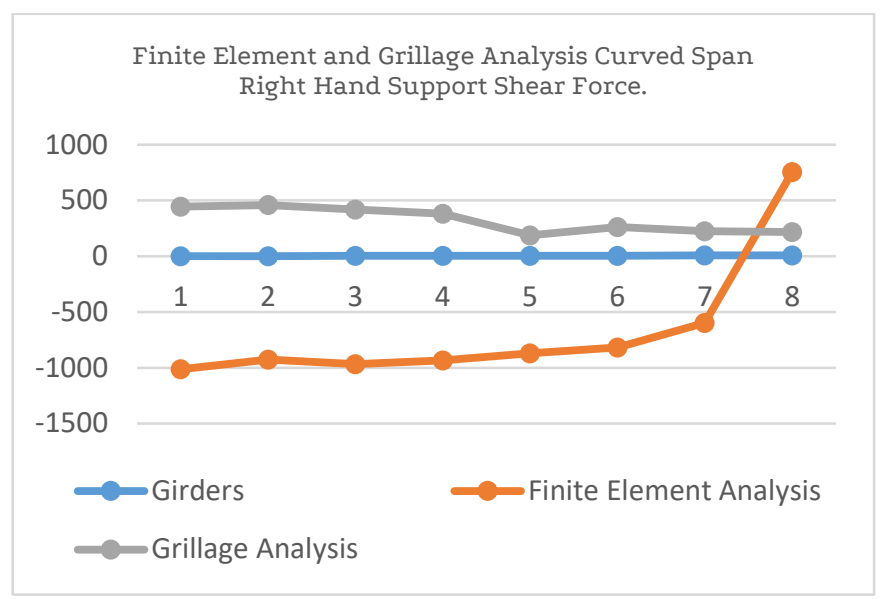

Figure 15. Grillage Analysis Results for maximum Shear Force at the Right-Hand Support of the Straight Span and the Left-Hand support of the Curved Span.

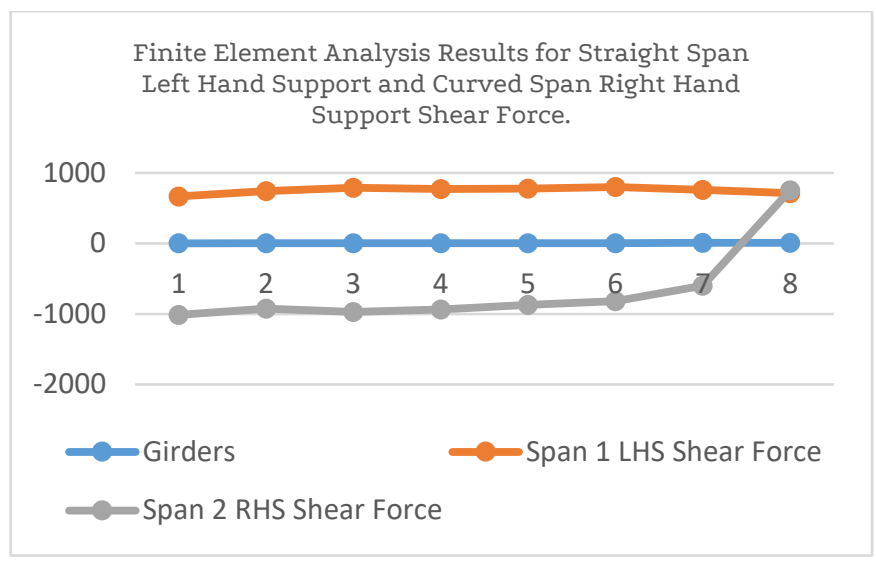

Figure 16. Finite Element Analysis Results for maximum Shear Force at the Left-Hand support of Straight Span and the Right-Hand support of Curved Span. 
Shear Force Results for Straight Span Left-

Hand Support and Curved Span Right Hand

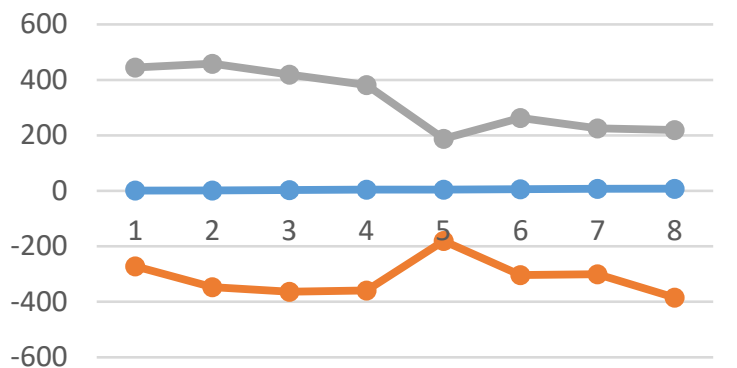

$-600$

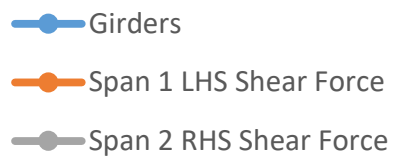

Figure 17. Grillage Analysis Results for maximum Shear Force at the Left-Hand Support of Straight Span and the Right-Hand support of Curved Span.

From figures 5-17, the following deductions are made;

While considering the maximum sagging moments at the mid-span, the finite element analysis results were higher than the results obtained from the grillage analysis as depicted in Figure $5-8$

From the grillage analysis result it was observed that, significantly higher values for intermediate support hogging moments were obtained as seen in Figure 9.

The results for the straight and curved deck varied proportionally to the span lengths, which varied due to curvature and varying arc lenghts of girders on the curved span. An interesting point of note was at girder " 4 " and " 5 " having span lengths of approximately " $21.4 \mathrm{~m}$ " and " $23.6 \mathrm{~m}$ " respectively which is quite close to the typical straight span length of "22.5". It can be observed that for these two girders there is just a slight variance in the results obtained when compared to the $22.5 \mathrm{~m}$ straight span girder.This is evident in the charts as the lines of the chart almost intersect at these locations as shown in Figures 7 and 8.

The shear force values obtained from either method for the straight and curved span are quite similar. This is depicted in the figures as in particular instances the comparative line diagrams are almost exact mirror images as shown in Figures 13, Chart 14, 16 and 17.

Besides comparing the flexural and shear stresses another important objective of the research was to investigate the impact of the increased torsional moments of the curved span on the other structural response values.

The torsional moment values were relatively higher on the curved span denoted with the location on girder " 0 " being the end support of the curved span, location on girder "22.5" being the intermediate support and location on girder "45" representing the end support of the straight span of the deck. Table 3.1 shows that the grillage analysis produced far higher torsional values along the curved span. Conversely, the finite element analysis depicted higher values for the straight span deck as depicted in table 3.2.
Table 3.1.Grillage Analysis results for Torsional Moments

\begin{tabular}{lcccccccc}
\hline & \multicolumn{8}{c}{ CSI Sap2000 Grillage Torsional Moments Combined } \\
Unfactored Load (KN.m)
\end{tabular}

Table 3.2. Finite Element Analysis Result for Torsional Moments

\begin{tabular}{lcccccccc}
\hline \multicolumn{7}{c}{ CSI Bridge FEM Torsional Moments Combined Unfactored } \\
Load (KN.m) \\
\hline $\begin{array}{l}\text { Location } \\
\text { on }\end{array}$ \\
\cline { 2 - 9 } Girder & $\mathbf{1}$ & $\mathbf{2}$ & $\mathbf{3}$ & $\mathbf{4}$ & $\mathbf{5}$ & $\mathbf{6}$ & $\mathbf{7}$ & $\mathbf{8}$ \\
\hline 0 & -587.8 & -614.8 & -568.1 & -523.7 & -495.3 & -447.8 & -436.5 & -297 \\
22.5 & -68.6 & -31.8 & -192.2 & -258.6 & -323.4 & -393.2 & -478 & -463.3 \\
22.5 & -11.2 & -17.6 & -2.3 & -4.0 & 1.3 & 32.4 & 77.9 & 57.7 \\
45 & -90.3 & -122.1 & -113 & -115.8 & -98 & -80.9 & -66.9 & -44.3 \\
\hline
\end{tabular}

Tabulated below are the results for deflection from the analysis. The values in Table 3.3 and Table 3.4 are deflection results from the grillage and finite element analysis respectively. It is evident from the tables that deflection values are more pronounced on particular girders in the grillage analysis, most notably girder 4-7. However, when comparing these values with those obtained from the finite element analysis run it becomes evident that there is a difference, as the finite element analysis result show relatively uniform deflection.

This compares considerably with findings by Medhat(2016)[8], where they concluded that results obtained from either the grillage and finite methods are significantly close and are safe for use in engineering design purposes. However, the impact of torsional moments in reducing mid-span sagging moments as concluded by Medhat(2016)[8]was not evident. This could be as a result of the continuity of the model as the case study model investigated in Medhat(2016)[8]was not continuous and even more so it was a composite structure. Thus, with our idealized model being a monolithic reinforced concrete model it can allude that the uniform stiffness of material made the impact of torsion on the span moments less pronounced.

Table 3.3. Total Deflection Obtained By Grillage Analysis For Unfactored Load At Different Locations On The Bridge Deck On

\begin{tabular}{lcccccccc}
\hline & \multicolumn{7}{c}{$\begin{array}{c}\text { CSI Sap2000 Grillage Total Deflection Combined } \\
\text { Unfactored Load (mm) }\end{array}$} \\
\cline { 2 - 9 } $\begin{array}{l}\text { Location on } \\
\text { Girder }\end{array}$ & $\mathbf{7}$ & \multicolumn{7}{c}{ Name of Girder } \\
\cline { 2 - 9 } & $\mathbf{1}$ & $\mathbf{2}$ & $\mathbf{3}$ & $\mathbf{4}$ & $\mathbf{5}$ & $\mathbf{6}$ & $\mathbf{7}$ & $\mathbf{8}$ \\
\hline 0 & 0 & 0 & 0 & 0 & 0 & 0 & 0 & 0 \\
9.75 & 3.6 & 7.4 & 15.1 & 24.6 & 48.6 & 68.4 & 85.3 & -0.5 \\
10 & 3.7 & 7.2 & 14.9 & 24.8 & 48.8 & 68.9 & 84.2 & 1.8 \\
10.25 & 3.4 & 7.2 & 14.1 & 24.2 & 48.9 & 69.3 & 99.2 & 3.6 \\
22.5 & 0 & 0 & 0 & 0 & 0 & 0 & 0 & 0 \\
25.31 & -4.5 & -8.6 & 0.2 & 1.0 & 1.0 & 0.9 & 1.3 & 0.2 \\
36.56 & 0.8 & 6.9 & 23.6 & 11.5 & 4.4 & 7.7 & 8.1 & 11.4 \\
45 & 0 & 0 & 0 & 0 & 0 & 0 & 0 & 0 \\
\hline
\end{tabular}


Table 3.4. Total Deflection obtained by finite element analysis for unfactored load at different locations on the bridge deck

\begin{tabular}{|c|c|c|c|c|c|c|c|c|}
\hline \multirow{3}{*}{$\begin{array}{l}\text { Location } \\
\text { on Girder }\end{array}$} & \multicolumn{8}{|c|}{$\begin{array}{l}\text { CSI Bridge FEM Total Deflection Combined } \\
\text { Unfactored Load ( } \mathrm{mm})\end{array}$} \\
\hline & \multicolumn{8}{|c|}{ Name of Girder } \\
\hline & 1 & 2 & 3 & 4 & 5 & 6 & 7 & 8 \\
\hline 0 & 0.3 & 0.15 & 0.16 & 0.16 & 0.16 & 0.17 & 0.13 & 0.001 \\
\hline 9.75 & 45.3 & 57.9 & 48.3 & 39.11 & 30.49 & 22.5 & 15.1 & 8.43 \\
\hline 10 & 45.3 & 58 & 48.4 & 39.19 & 30.59 & 22.5 & 15.1 & 8.46 \\
\hline 10.25 & 45.3 & 58 & 48.4 & 39.21 & 30.59 & 22.6 & 15.2 & 8.48 \\
\hline 22.5 & 1.5 & 1.8 & 1.52 & 1.08 & 5.96 & 1.2 & 1.7 & 2.31 \\
\hline 25.3 & 4.7 & 3.8 & 3.4 & 3.58 & 3.19 & 3.8 & 4.7 & 5.61 \\
\hline 36.7 & 13.2 & 12.7 & 12.2 & 11.6 & 11.61 & 12.7 & 13.4 & 14.73 \\
\hline 45 & 0.12 & 0.11 & 0.11 & 0.11 & 0.11 & 0.12 & 0.1 & 0.14 \\
\hline
\end{tabular}

\section{Conclusions and Recommendations}

The results from investigation on structural response of the bridge decks has led to the following conclusions;

From design perspective, the grillage analysis results is more conservative with regards to sagging moments and shear force while finite element analysis results is more conservative for to support hogging moments.

The finite element analysis produced higher values for deflection but the values for the grillage analysis were close enough and the disparity was insignificant. The torsional moments has a very large disparity in results from the grillage analysis when compared to the finite elemen analysis. And this is certainly due to the grillage model being less torsionally stiff in comparison to the finite element model thereby making the grillage model more susceptible to torsional deformation.

Deducing from research done by Ajagbe et al, (2014)[14], where the finite element analysis results were compared with analytical methods to analyze a free-standing staircase. It was concluded that the finite element approach is robust and can be adapted to solving even very complex structures. This was affirmed in this study as the finite element results seems to exhibit a better distribution of stresses due to its increased stiffness when compared to the grillage approach which is less stiff and very close to the analytical approach. Hence, for structures with curves, it is much better to adopt a finite element approach for better analysis.

\section{Acknowledgement}

We acknowledge the contribution of the Department of Civil Engineering of The University of Ibadan, Nigeria towards the conduct of this research

\section{Declaration of Conflict of Interests}

On behalf of all authors, the corresponding author states that there is no conflict of interest. They have no known competing financia interests or personal relationships that could have appeared to influence the work reported in this paper.

\section{References}

[1.] BS 5400-2:2006 Steel, Concrete and Composite Bridges- Part 2: Specification of loads.

[2.] Design Manual for Roads and Bridges BD 37/01 Volume 1, Loads for Highway bridges, 2001.

[3.] Himansha, J., and Yogesh B., Effects of skewness on three-span reinforced concrete $\mathrm{T}$-Girder bridges. International Journal Computational Engineering Research (IJCER) Volume 04 Isuue 8 (2014). ISSN(e):2250-300511

[4.] Pranathi, R., And Karuna, S., Comparative study on Normal and Skew Bridge of PSC Box Girder. International Journal of Research in Engineering and Technology volume 04 issue 06, (2015),112-117. eISSN: 2319-1163/pISSN:2321-7308.

[5.] Timoshenko, S., History of the strength of materials, McGraw-Hill New York(1953).

[6.] Truesdell, C. The rational mechanics of flexible or elastic bodies. Societatis scientiarum naturalium Helveticae/Orell Fussli Turici (1960)1638-1788.

[7.] Hambly, E.C., Bridge Deck Behavior. Second Edition E \& F.N. Spon (1976) ISBN 0-419-17260-2.

[8.] Medhat, K.A., Parametric study of the structural behaviour of horizontally curved bridge deck.life science journal, volume 13 issue 2 (2016)101-111. ISSN:1097-8135.

[9.] CSI Computers and Structures Inc, "Sap2000", version 22, 2020.

[10.] CSI Computers and Structures Inc, “CSI Bridge”, version 21, 2019.

[11.] Muller, R.K., Small scale modelling of reinforced concrete structures. Taylor \& Francis Routledge (1992) ISBN:1851666710.

[12.] [12] Van Siclen, R.C., Small scale modelling of Concrete models. Joint Highway Research Project No 15 July 1968.

[13.] Gang, X., Wang, D., and Su, J.X., A new similitude analysis method for a scale model test. Key Eng. Mater 439-440(2010)704-709.

[14.] Ajagbe, W.O., Rufai, O.A., and Labiran, J.O., Finite Element Analysis of a Free-Standing Staircase. Nigerian Journal of Technology (NIJOTECH) Vol. 33 No. 4,(2014)610-617. ISSN:1115-8443 www.nijotech.com.

\section{How to Cite This Article}

Buari T.A., Olutoge F.A., Ayininuola G.M, Agbanah-Owa O.A. Parametric study on structural behavior of a two-span continuous bridge deck and a curved span deck, Civil Engineering Beyond Limits, 3(2021), 1-7. https://doi.org/10.36937/cebel.2021.003.001 